\title{
Theoretical perspective on the interplay between ICT and quality of life
}

\author{
Gunilla Bradley \\ Royal Institute of Technology, Stockholm, Sweden, Bradlev@it.kth.se
}

\begin{abstract}
An interdisciplinary research program on "Computer technology and work life" was initiated and led by the author at Stockholm University from 1974 to 1988. The program inspired many other research programs in Sweden in the field. A theoretical framework was developed including two theoretical models, one more general and one where the concepts and their interrelationships were specified. The models were tested empirically in three large work organisations in Sweden, representing three main historical periods of computer technology. It was also used as a model in discussing what might be desirable goals in the information society. The present fourth period, the "Network period", is characterised by a convergence of three main technologies: computer technology, telecommunication technology, and media technology (ICT). ICT is used in almost every activity and embedded in many things around us. The author proposes a superimposed theoretical model reflecting "ICT and psychosocial life environment", a revised model of her initial models. Finally, future research is discussed with reference to theoretical models revised, and conclusions address major psychosocial processes, psychosocial life environments and a call for synthesis.
\end{abstract}

Key words: Information Society; Work Life; Network; Social impact; Quality of Life, ICT

\section{BACKGROUND}

The development of new technology - advanced and widespread use of computer technology and telecommunications and the integration of these technologies - have a profound impact on organizational and quality aspects

The original version of this chapter was revised: The copyright line was incorrect. This has been corrected. The Erratum to this chapter is available at DOI: 10.1007/978-0-387-35609-9_29 
of our lives today both at work and at home. New application areas within information technology industry are emerging at the convergence of communications, computer, and media. IT and ICT are used synonymously in the following context.

The paper consists of two parts. The first is a description of the theoretical model. The second is a presentation of trends and visions for the quality of life in the future.

\section{THEORETICAL MODEL ON COMPUTER TECHNOLOGY AND WORK LIFE}

The RAM research programme on "Computer technology and work life" was an interdisciplinary research programme initiated and led by Bradley at Stockholm University from 1974 to 1988 . RAM referred to the Swedish expression for "Rationalisation" and "Work Environment". A theoretical framework was developed by G. Bradley entitled "Computer Technology and Working Environment" (first published in 1977). The framework included two theoretical models, one more general (figure 1) and one model where the concepts and their interrelationships were specified (Bradley 1977, 1989). The models were empirically tested in three large work organisations in Sweden, representing three main historical periods of computer technology - from systems with batch processing to microcomputerisation. The psychosocial work environment was considered in terms of the following perspectives:

-three levels of analyses (individual, organisational, societal)

- objective and subjective work environments

-interplay between levels

-interplay between objective and subjective work environments

-interplay between working life and private life

-a life-cycle perspective.

The content of some of the concepts in the models may be summarised as follows. The objective work environment refers to areas of work that are germane to large groups of employees. The subjective work environment consists of perceptions and attitudes related to corresponding sets of factors in the objective work environment. The subjective work environment is closely linked to the concept of job satisfaction. 


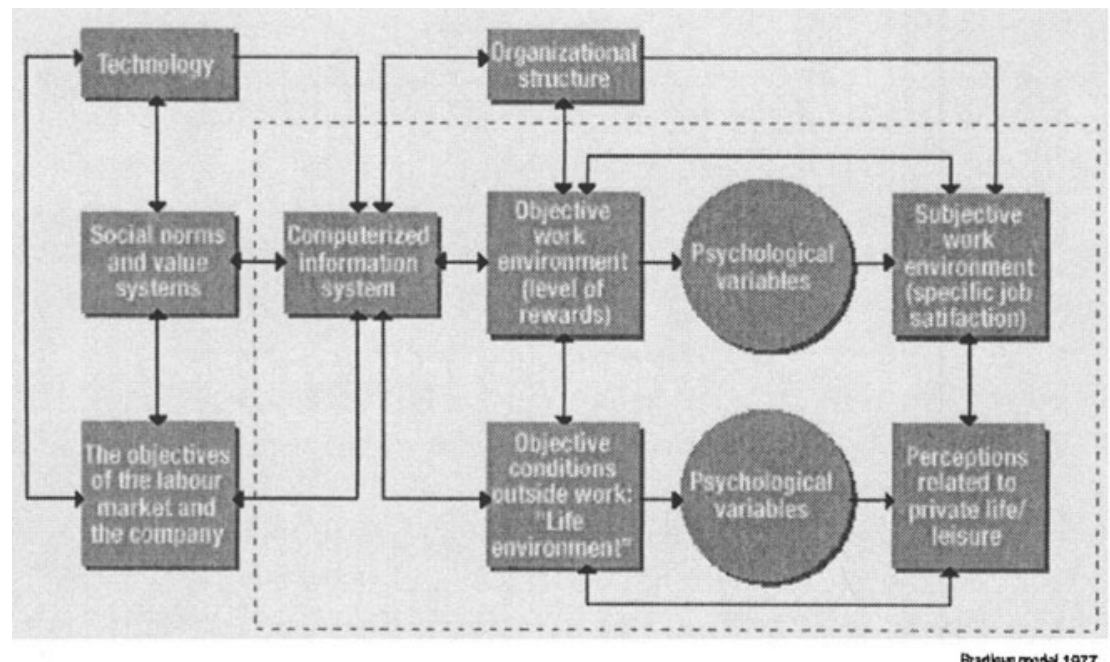

Figure 1. Theoretical model on Computer technology and work environment (Bradley 1977, 1989)

Psychological variables is a general term covering a number of intermediate, psychologically relevant variables such as the level of aspiration and the weight attached to specific work-environment areas. These variables are essential if one wishes to understand and explain the subjective work environment and its dynamics and also the perceptions of the conditions that govern our lives in general. They are crucial in the analysis of subgroups of employees and cultural variations.

The concept of psychosocial refers to the process involving the interaction between the objective environment and the subjective one. Essential concepts within the psychosocial work environment include factors such as contact patterns and communication, organisational structure and design, work content and workload, participation in decision-making, promotional and development patterns, salary conditions and working hours.

The term psychosocial work environment is used to signify the course of events or the process that occurs when objective factors in the environment are reflected in the individual's perception (either positive or negative) of work and conditions of work. Its essence is the interaction between the environment and the individual. Thus work environment factors exist at different levels - the level of society, the level of the company and the level of the individual - and they interact with one another. But there is also a distinction between the objective and the subjective work environment, which also interact (Bradley 1989).

Objective conditions outside work refers to behaviour and consumption, the conditions that prevail during the hours spent away from work. These 
may be affected by change related to the use of computerisation at work. Certain attitudes, values and experiences related to private life/leisure and family life were also analysed against the background of the introduction of computer technology into the individual's work.

The theoretical models used in the RAM programme can also be used as models in discussing what structure a computerised society should have (see the two-way arrows in the figure) and what might be desirable goals. This was also done in a special chapter on actions strategies in Bradley (1986) and also in my chapter in the book Computers and Society (Beardon 1993).

An extensive research strategy was applied with qualitative and quantitative methods for collection and analysis of data. Indices were created through multivariate analysis, and they corresponded well to the theories in the field of work and organisational theory. I limit myself to give the structure of indices and a shortened description of the content of the indices (p. 217, Bradley 1989): Work Psychosocial Environment Factors (16 indices); Physio-ergonomic Work Environment (4 indices) Democracy at Work (5 indices); Effects of the Display Terminal Information system (14 indices); Effects of the Personal Computer system (11 indices); Health Problems at Work (5 indices); Health Problems during Leisure Time (6 indices); The Effects of Work on Leisure /Time/Family Life (3 indices); The Weight Attached to Specific Work Environment/ Factors and the General Attitude to Work (4 indices).

From the empirical experiences a checklist was developed to be used in the evaluation of a project for implementing computer systems or systems in use, to give a rapid assessment of which aspects of the work and working conditions are to improved and developed. Key words, were specified and were complemented with examples of areas to be selected for analysis, design and action.These measures and tools are still relevant for studies of the social and organisational impact of ICT. Theories, methods and results from the RAM programme are summarised in "Computers and the psychosocial work environment" (Bradley 1989). In later projects a fourth period in the evolution of computer technology both the psychosocial and the societal impact of ICT has been in focus, best referred to in our research programme entitled "Interplay ICT - Humans - Society".

The broader view in the RAM project was early presented at international conferences and the tools were early translated to English. It inspired both research in Sweden and in other countries. Many projects focused specific aspects of the organisational work environment related to computerisation and IT. In Bradley 2001 some main international research projects are summarised focusing on the changes in work and quality of work. 


\section{THEORETICAL MODELS REVISITED}

The fourth and present period of computerisation I would like to refer to as the "Network period", very much based on the convergence and integration of three main technologies. ICT is more and more being used in almost every activity and embedded in most of things around us. The graphical representations in the models need to be changed.

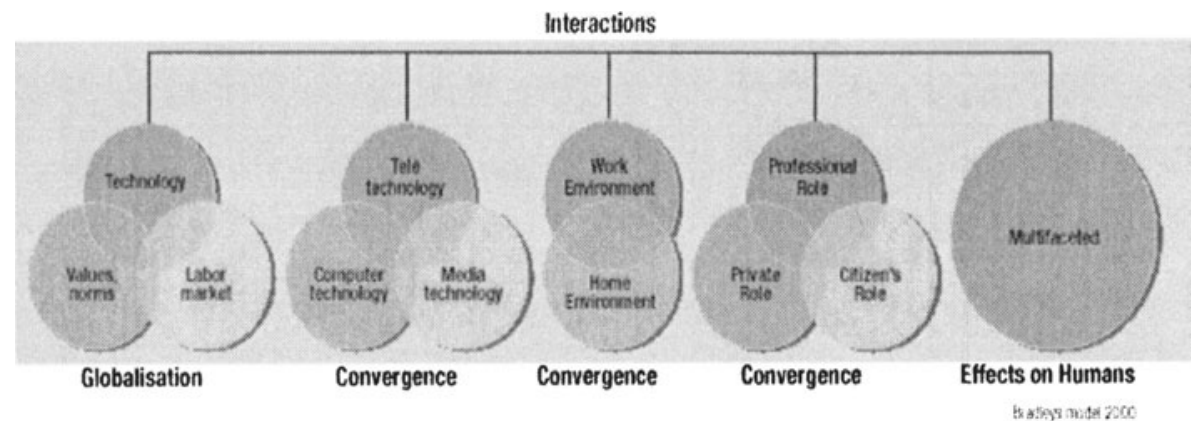

Figure 2. Convergence Model - ICT and Psychosocial Life Environment (Source: Bradley 2001)

Comments to the model:

- A convergence of computer technology, telecommunication technology and media is occurring

- Professional Role (Work Life) and Private Role (Private Life) and Citizen's Role also converge

- Work Environment and Home Environment are converging to become Life Environment

- Effects on the Individual become more multi faceted and complex. This is valid both regarding the psychological and the physical effects.

- Technology, Norms and Values and Labour Market - interact in the globalisation process

- A new emphasis on certain dimensions in the psychosocial environment.

- New dimensions are appearing in the psychosocial environment. Openness for unforeseen implications is required.

Within informatics a discussion of focus is taking place: both analysis and design need to address not only the work process and management connected to the sphere of production life, but also people's life environment. Not only professional roles but also our roles as citizens and private persons are crucial. In the next section this area will be addressed under the heading "The home as a virtual and physical space". 
Community research in a broad sense comes to the fore, with respect to both physical and virtual communities. Analysis and design of ICT and societal systems both at local level and globally become important. The labour market parties in the Nordic countries used to play a role in system development and research in informatics and ICT-related disciplines in the $70^{\prime}$ th. A renewal of the structures and focus within these organisations is going on in Sweden and in Europe. There is also a need for new and additional actors at the deeper and broader integration of ICT in the society (children, elderly, and consumer organisations).

Systems design, societal design, regional planning, organisational design and role design, which could all be represented by converging circles, are issues for the emerging IT-related disciplines. Of course, more traditional fields like architecture, industrial design and graphic design will be involved.

The convergence model involves a paradox. At the same time as convergence and the blurring of boundaries occur, a parallel fragmentation process is going on, with a re-forming and hardening of social divisions. This is often referred to as the "digital divide". This split could be analysed both on various levels of analysis. The convergence in technology and in life environment seems to cause an increased stress level and overstimulation in the western industrialised countries. The gap between "those who have" and "those who have not" seems to increase.

\section{THE HOME AS A VIRTUAL AND PHYSICAL SPACE}

The overall purpose of the ongoing research project "Home of the Future" concerns changes in living and working conditions with emphasis on the impact of ICT (Chapter 11 page 197, in Bradley 01). The objective of two pilot studies has been to explore future trends of living and working from and at home at the increased use of ICT related services and products. The first study focused USA and the second South East Asia. The method has been explorative, using expert interviews with leading research institutes, universities, and high tech companies. Both the initial theoretical models and the convergence model are applied. A third approach is to use the "Home of the Future Model" (Bradley L. et al 2000) in the analyses of factors effecting the future home. From that model problems are derived e $g$ What human needs and behavior are related to the home and home environment? What new behaviors evolve on the border between technology and human needs? What are the main social trends? What are the main technological trends? What are the main hypotheses that could be phrased from an international comparative perspective? Some main experiences are presented below. 


\subsection{Some social trends}

Some of the following trends are commented more in $4.2-4.4$.

- We will become more global, but also more local - "glocal" is a concept describing the development

- We will develop new forms of living - for example "flexible living" supporting the mobile person/lifestyle and "community living" supporting traditional values

- We will "choose" new forms of working and our working conditions will change

- We will be "Working from Home" and "Homing from Work"

- We will have an overflow of information and communication

- New physical meeting places will appear and virtual meeting places

- Family ties will be strengthened, the neighborhood will be revitalized and the cooperation with the schools will be facilitated

- The definition of a family will be changed - we will consider the extended family encompassing relatives, friends and colleagues. The nuclear family will not be the only norm for family life

- Our homes are getting some functions of a virtual market place

- Our citizen's role is possible to strengthen

- Under certain circumstances there are possibilities to strengthen and deepen democracy

- There is a risk for a "digital divide" regarding living and dwellings.

\subsection{Home as a communication sphere}

Our studies show that "the home" will be increasingly associated with the communication sphere we normally are in contact with in our lives. Many activities traditionally performed at home (the physical home), can now be performed "on distance" (the virtual home) such as private phone calls, personal entertainment through TV and radio, planning and handling of private documents. More mobile IT equipment in our lives will make it easier to perform "home activities" on distance in the same way as we can perform job activities on distance. "Working from Home" and "Homing from Work" are hence key issues in our analysis. 


\subsection{Borderless home and borderless society?}

The results show that it becomes more and more difficult to set boundaries to what represents our home. In the same way, setting boundaries to the work place has become complex. Will this new drifting border between home and the surrounding society change the individual and indirectly the society? Research within telecommunication claims that "death of distance" will impact our lives to the same extent as the use of electricity once made.

\subsection{Home of the Future - a discussion}

Our study has shown that more and more market activities take place within the home (physical) such as billing, shopping, booking, entertaining etc, and are supported by the use of ICT. Along with increased market activities in homes comes an increase in contacts and communication. Our home becomes our main communication hub in a sense.

The big challenge in the near future is the home in a broad sense, as many human roles are converging to one life role and the home is more and more understood in terms of virtual space as well as physical. Driving forces are converging and embedded technologies. The following trends are enforcing the home as a communication sphere and the basis for a lot of activities and feelings which are connected to human needs:

- The home as the extended family center

- The home as a care center

- The home as a multimedia center

- The home as a center for democratic dialogue

- The home as a market place

- The home as a learning center

What is important for the design of the home of the future? We think from the results that it is important with a holistic view of the functions of the home, such as family life and activities, learning, work, hobbies, and entertainment. The design of our homes should take into account that technology is a natural part of the home, where all details are not seen and do not need our attention. A "smart home" should be service and not product oriented. A "smart home" should help the individual to good health, safety and joy. According to our results a "smart home" should be a place to land on, where you can say "stop". A "smart home" should enable us to deepen human qualities and provide humans with psychological and physical strength to change society in a humane direction..

The design of the future home should be based on human needs, as well as human abilities and preferences. Important human needs are the need for 
having a safe and secure life, the need to influence our life conditions, the need for social belonging, the need for learning and developing oneself, and finally our need for meaningful life content. These human needs can be materialized into certain activities, behavior and experiences at home and at work. The design should aim at enriching the individual's experience at home by creating quality time, facilitating communication, interaction and entertainment, automating certain activities such as maintenance and payments, and establishing a "home sphere" for communication. Theories on human needs, physical as well as psychosocial, could be used as a point of departure for analyzing how we could design and create a good home environment in the information society.

In parallel it is important to prevent various stress phenomena in our future homes. Stress in the Internet world is related to information overload, contact overload, demands on availability, lack of "filters", difficulty of separating "noise" from essentials, and changing level of expectations on the individual. The altered perception of time and space in general in the society is a per se a stress factor. The actions that have to be undertaken are on the society, company, community and individual level.

\section{FUTURE RESEARCH RELATED TO THE MODELS}

\subsection{Focus on Psychosocial Life Environment/Quality of Life and Well Being}

I think that when we have been living in a society deeply and broadly affected by the new technology, it might be harder to identify both risks and opportunities. A new generation is here, which has grown up in the digital environment. There are reasons today to go back to classics in research: e.g., there are no more work environments in the traditional sense - they are dissolving, but phenomena identified in work life research, where Scandinavia during many years was very active, have to be reviewed with a new perspective. How are human needs of influence, belonging and meaning met in the new structures? In the development of "the Home of the Future", there is a growing market for all kinds of ICT applications - services and equipment. We need to analyse and design the good home - when our roles are integrating. 


\section{2 Focus on the effects on the individual and on humans}

Some examples of desirable research focusing the individual are:

- How is ICT changing our identity and self-perception; social competence; creativity; integrity, and trust? How is ICT changing the following:

- Being connected and not being connected

- Things and services

- Balance between emotional and rational components

- Balance between female and male

- Involvement and alienation

- Individual and collective

\subsection{Focus on some major psychosocial processes as policy statements}

One way to summarise the discussion on the IT society and the individual is to address psychosocial processes. They could be formulated as policy statements or viewed as research questions. By now there are reasons to start up normative research which later on could be discussed across wider cultures. It concerns the classic question: Is research value-free?

Integration or Isolation: Normatively, ICT should contribute to an enrichment in the social contact between people and should be used to prevent social isolation and facilitate integration.

Autonomy or control: ICT should contribute to a greater autonomy for the individual. Control or freedom is a classic issue often described in the terms of "privacy - integrity".

Overstimulation or understimulation: ICT should facilitate information access for all and support individual learning, but at the same time prohibit various kinds of overload e. g., information overload, contact overload.

Dehumanisation or Humanisation: ICT should contribute to the deepening and development of true human qualities and be used to provide time for people to develop themselves as human beings.

$\boldsymbol{E}$ - conflicts (wars) or E-co-operation (peace): E-conflicts must be avoided. E-co-operation and peace are major concerns. 


\subsection{Focus on syntheses}

We need to focus on syntheses. Again I think there is a need for normative research in the next step where we place human welfare and life quality for all as crucial societal goals.

\section{REFERENCES}

Beardon, C \& Whitehouse D (Eds.) (1993). Computers and Society. Oxford: Intellect.

Bradley, G. (1977). Computer Technology, Work Life, and Communication.

The Swedish delegation for long term research. FRN. Stockholm: Liber (In Swedish).

Bradley, G. (1979). Computerization and some Psychosocial Factors in the Work

Environment. Proceedings of the conference Reducing Occupational Stress, New York, 1977. NIOSH Publication No. 78-140, p 30-40. U.S. Department of Health, Education, and Welfare.

Bradley, G. (1989) (publ. in Swedish 1986). Computers and the Psychosocial Work Environment. London/Philadelphia: Taylor \& Francis.

Bradley, L., Andersson, N., Bradley, G. (2000). Home of the Future - Information and Communication Technology (ICT) - changes in society and human behavior patterns in the net era. FSCN research report R00-1. http://www.mh.se/fscn

Bradley G. (2001). Humans on the Net. Information and Communication Technology (ICT Work Organization and Human Beings. Stockholm: Prevent. ISBN 91-7522-701-0. 